\title{
Aplikasi Kondensor pada Penyulingan Minyak Cengkeh di Desa Kare Kabupaten Madiun
}

\author{
Nur Ihda Farikhatin Nisa ${ }^{1}$, Dyan Hatining Ayu Sudarni ${ }^{2}$, Achmad Aminudin ${ }^{3}$ \\ ${ }^{1,2}$ Teknik Kimia, Fakultas Teknik, Universitas PGRI Madiun - Jl. Auri No. 14-16 Madiun \\ ${ }^{3}$ Mesin Otomotif, Jurusan Teknik, Politeknik Negeri Madiun - Jl. Serayu No. 84 Madiun \\ E-mail: nurihda_fn@unipma.ac.id. No. Hp: +6285731469696
}

\begin{abstract}
ABSTRAK
Minyak cengkeh merupakan salah satu produk minyak atsiri yang dihasilkan dari Desa Kare Kecamatan Kare Kabupaten Madiun. Di desa tersebut terdapat beberapa kelompok usaha penyulingan minyak cengkeh, salah satunya adalah Kelompok Usaha "Rejo Tumetes". Proses penyulingan di kelompok usaha tersebut dilakukan di unit penyulingan yang terdiri dari 1 (satu) buah ketel tangki destilasi, tungku pemasakan atau furnace, pendingin yang berupa pipa yang dicelupkan ke dalam kolam pendingin yang berukuran panjang 7,5 meter dengan lebar 3,5 meter dan kedalaman 1,5 meter yang dilengkapi dengan pemisah produk minyak cengkeh berupa drumdrum bertingkat. Pendinginan merupakan hal terpenting dari proses penyulingan, jika pendinginan kurang optimal maka minyak yang dihasilkan juga tidak maksimal. Hal ini dikarenakan tidak semua minyak yang terikut uap air bisa terembunkan. Permasalahan yang dihadapi mitra saat ini adalah proses kondensasi yang belum maksimal dikarenakan masih menggunakan kolam pendingin. Untuk menyelesaikan permasalahan tersebut, kami membuat sistem pendingin berupa kondensor dalam Program Pengabdian Kepada Masyarakat ini. Untuk mencapai target luaran sesuai permasalahan yang dihadapi, digunakan beberapa rencana kegiatan yaitu meliputi penyuluhan, demonstrasi dan pelatihan, kunjungan lapangan, pengadaan peralatan serta pendampingan dan monitoring evaluasi diikuti oleh Kelompok Usaha "Rejo Tumetes" di Desa Kare. Hasil dari program ini yaitu tercapainya kelompok usaha penyulingan yang mampu membuat dan mengoperasikan kondensor secara mandiri agar proses pendinginan uap minyak cengkeh dapat berjalan sempurna dan minyak cengkeh yang dihasilkan semakin banyak.
\end{abstract}

\section{Kata kunci : cengkeh; minyak atsiri; kondensor}

\begin{abstract}
Clove oil is one of the essential oil products produced from Kare Village, Kare District, Madiun Regency. In the village there are several clove oil refining business groups, one of which is the "Rejo Tumetes" Business Group. The distillation process in the business group is carried out in a distillation unit consisting of one distillation tank, furnace, cooling in the form of a pipe dipped in a cooling pond measuring 7.5 meters long with 3.5 meters wide and a depth of 1.5 meters equipped with separating clove oil products in the form of multi-level drums. Cooling is the most important thing from the refining process, if the cooling is not optimal then the oil produced is also not optimal. This is because not all the oil that comes with water vapor can be condensed. The problem faced by partners at this time is that the process of condensation has not been maximized because it still uses a cooling pool. To solve this problems, we made a cooling system in the form of a condenser in this Community Service Program. To achieve the target output in accordance with the
\end{abstract}

Cara Mengutip : Nisa, N. I. F., Sudarni, D. H. A., Aminudin, A. (2019). Aplikasi Kondensor pada Penyulingan Minyak Cengkeh di Desa Kare Kabupaten Madiun. JAST : Jurnal Aplikasi Sains dan Teknologi, 3 (2), 122-128. doi:http://dx.doi.org/10.33366/jast.v3i2.1481 
problems faced, several activity plans are used which include counseling, demonstrations and training, field visits, procurement of equipment as well as mentoring and monitoring evaluation followed by the "Rejo Tumetes" Business Group in Kare Village. The result of this program is the achievement of a refining business group that is able to make and operate the condenser independently so that the clove oil vapor cooling process can run perfectly and more clove oil produced.

Keywords : cloves; essential oils; condensers

\section{PENDAHULUAN}

Menurut laporan Dinas Perkebunan Provinsi Jawa Timur, komoditas atsiri yang ada dan sudah diusahakan secara komersial adalah minyak cengkeh, nilam dan kenanga [1]. Salah satu sentra minyak cengkeh di Propinsi Jawa Timur adalah Kabupaten Madiun, tepatnya di Desa Kare Kecamatan Kare. Di desa tersebut terdapat beberapa kelompok usaha minyak atsiri, salah satunya Kelompok Usaha "Rejo Tumetes" yang diketuai oleh Matius S. Santoso. Minyak atsiri yang dihasilkan Kelompok Usaha "Rejo Tumetes" adalah minyak cengkeh. Daun cengkeh kering sebagai bahan baku utama diperoleh dari petani cengkeh di lingkungan sekitar ataupun dari petani Kabupaten Ponorogo. Daun cengkeh kering tersebut dibeli dari petani dengan harga 2500-3000 rupiah/kg. Tingkat harga tersebut sangat tergantung pada musim. Pada musim kemarau, kandungan minyak dalam daun cengkeh sangat tinggi sehingga harga belinya juga tinggi. Sedangkan pada musim hujan kandungan air lebih banyak pada daun cengkeh yang menyebabkan harga belinya jauh lebih murah.

Minyak atsiri sendiri umumnya dihasilkan dari proses penyulingan [2]. Secara umum ada tiga macam sistem distilasi yaitu penyulingan dengan air; penyulingan dengan air dan uap; dan penyulingan dengan uap langsung [3], [4],
[5]. Penyulingan yang dilakukan oleh Kelompok Usaha "Rejo Tumetes" adalah penyulingan dengan air dan uap (water and steam distillation), dimana bahan baku dan air tidak bersinggungan langsung karena dibatasi dengan saringan diatas air. Cara ini adalah yang paling banyak dilakukan pada dunia industri karena cukup membutuhkan sedikit air sehingga bisa menyingkat waktu proses produksi. Dimana dalam sekali penyulingan minyak cengkeh, kelompok usaha ini membutuhkan waktu penyulingan selama 8-9 jam. Sehingga dalam sehari bisa dilakukan dua kali penyulingan minyak cengkeh dengan kapasitas penyulingan enam kwintal untuk sekali pengolahan.

Untuk proses pendinginan uap minyak cengkeh, Kelompok Usaha "Rejo Tumetes" menggunakan kolam pendingin yang berukuran panjang 7,5 meter dengan lebar 3 meter dan kedalaman 1,5 meter. Air pendingin di pompa dari sungai kecil disekitar lokasi penyulingan yang berjarak sekitar $500 \mathrm{~m}$ dan dialirkan menuju kolam pendingin. Dalam sekali penyulingan dihasilkan $15 \mathrm{~kg}$ minyak cengkeh dengan rendemen sekitar $2 \%$ dan dijual pada tengkulak dengan harga 120000/kg. Gambar unit pengolahan minyak cengkeh ditunjukkan pada Gambar 2 di bawah ini. 


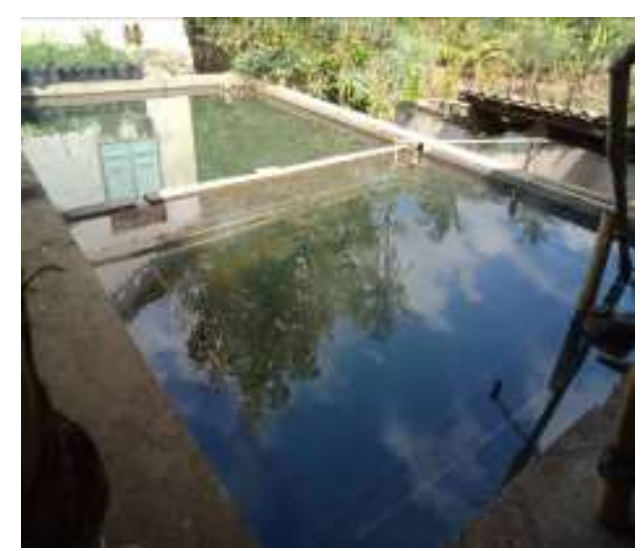

(a)

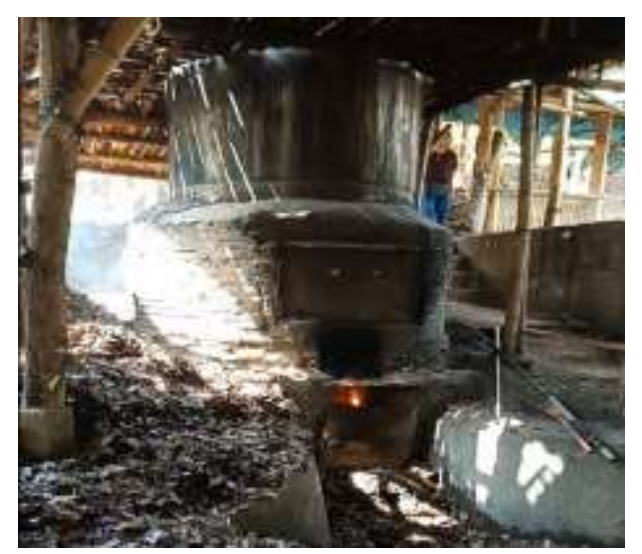

(b)

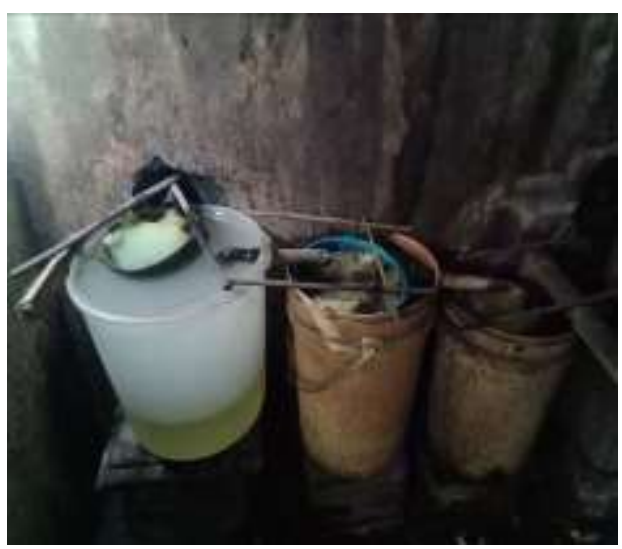

(c)

Gambar 2. Unit penyulingan minyak cengkeh (a) Kolam pendingin (b) Tungku masak (c) Drum penampung minyak

Pada Gambar 2 dapat dilihat bahwa kolam pendingin yang digunakan pada unit penyulingan minyak cengkeh terdiri dari dua kolam yaitu kolam dingin yang berasal dari air sungai dan kolam panas tempat pendinginan uap minyak cengkeh. Dimana antara kolam yang satu dengan yang lainnya saling berhubungan satu sama lain. Ketergantungan kelompok usaha penyulingan minyak cengkeh terhadap ketersediaan air sungai ini sangat tinggi. Pada musim kemarau penyuling minyak cengkeh mengalami kesulitan dalam mencari sumber air sehingga diperlukan alternatif lain yang dapat digunakan untuk pendinginan uap minyak cengkeh agar proses penyulingan minyak cengkeh bisa berjalan maksimal.

\section{METODE KEGIATAN}

Berikut ini adalah metode pelaksanaan dari solusi permasalahan yang telah diuraikan di atas.

\section{A. Tahapan Pelaksanaan Kegiatan}

Berdasarkan hasil survey yang telah dilakukan oleh tim, didapatkan permasalahan yang dihadapi oleh mitra seperti yang telah dipaparkan di atas. Dari permasalahan yang ada, maka tim pengusul berusaha untuk menciptakan suatu ide kreatif dan inovatif dengan tujuan memberikan suatu teknologi untuk meningkatkan kualitas dan kuantitas produksi minyak cengkeh. Strategi yang dilakukan dalam kegiatan ini yaitu dengan cara membuat alat pendingin berupa kondensor dalam proses penyulingan minyak cengkeh. Disamping itu, dilakukan penyuluhan, pelatihan dan pendampingan kepada mitra untuk pengenalan dan penerapan teknologi tepat guna tersebut. Berdasarkan masalah yang dihadapi mitra, akan dilakukan beberapa tahapan kegiatan sebagai solusi 
permasalahan dimana pelaksanaannya diuraikan sebagai berikut:

a. Survey lokasi dan sosalisasi kegiatan

b. Membuat rancangan alat dan proses

c. Pembuatan alat

d. Uji operasi dan aplikasi alat

e. Pelatihan dan sosialisasi penggunaan alat

\section{a. Observasi Lapang}

Untuk mencari masukan permasalahan yang ada di mitra maka dilakukan pertemuan dan berdiskusi dengan Kelompok Usaha "Rejo Tumetes" (mitra) dan juga dilakukan observasi lapang yang bertujuan untuk :

1. Mengamati proses penyulingan minyak cengkeh yang digunakan.

2. Mengamati kualitas dan kuantitas minyak cengkeh yang dihasilkan.

\section{b. Perancangan Kondensor}

Perencanaan dan perancangan merupakan langkah awal dari pembuatan alat. Perencanaan pembuatan alat ini harus dilakukan dengan benar agar alat yang dibuat nanti dapat bekerja secara maksimal.

\section{B. Kegiatan Transfer/ Alih Teknologi a. Penyuluhan dan Diskusi}

Kegiatan ini dilakukan dengan mengumpulkan khalayak sasaran strategis (Kelompok Usaha "Rejo Tumetes") untuk mengikuti penyuluhan, ceramah dan diskusi tentang teknologi penyulingan minyak cengkeh.

\section{b. Demonstrasi dan Pelatihan}

\section{Penggunaan alat}

Demonstrasi dan praktek tentang penggunaan kondensor pada sistem penyulingan. Setelah demonstrasi, Kelompok Usaha "Rejo Tumetes" didampingi dan dibina secara intensif yang dikoordinir oleh ketua Kelompok Usaha "Rejo Tumetes".

\section{c. Konsultasi dan Pendampingan}

Kegiatan ini dilakukan secara periodik untuk membina dan mendampingi khalayak sasaran strategis sampai berhasil memanfaatkan teknologi tersebut. Selain itu, penyuling minyak cengkeh bisa berkonsultasi tentang pelaksanaan program pengabdian kepada masyarakat sampai bisa mencapai hasil yang maksimal.

\section{Monitoring dan Evaluasi Kegiatan \\ a. Evaluasi Sebelum Pelaksanaan \\ Kegiatan}

Indikator yang digunakan meliputi kesanggupan, antusiasme dan kemampuan khalayak sasaran mengikuti kegiatan yang akan dilakukan, tingkat kerjasama dengan mitra dan lapisan masyarakat terkait dalam pelaksanaan pengabdian kepada masyarakat.

\section{b. Evaluasi Selama Kegiatan \\ Berlangsung}

Indikator yang digunakan meliputi pemahaman khalayak sasaran terhadap materi kegiatan, kemauan dan motivasi untuk mengimplementasikan dalam kehidupan sehari-hari serta sustanability mitra terkait untuk melanjutkan dan membina khalayak sasaran agar mencapai hasil yang maksimal.

\section{c. Evaluasi Setelah Kegiatan Selesai}

Indikator yang digunakan meliputi minat dan kemampuannya untuk bisa melanjutkan hasil Pengabdian Kepada Masyarakat, pelatihan serta pembinaan dalam peningkatan jumlah produk.

\section{Partisipasi Mitra}

Partisipasi mitra diperlukan dalam mensukseskan terlaksananya program ini, antara lain: 
a. Memberikan informasi data-data kondisi penyulingan minyak cengkeh

b. Memberi masukan tentang bentuk alat, kapasitas alat yang diharapkan

c. Mendukung pelaksanaan pelatihan pengoperasian alat

d. Mempelajari perawatan alat

e. Berkoordinasi secara aktif dengan pelaksana program Pengabdian Kepada Masyarakat.

\section{KARYA UTAMA}

Teknologi tepat guna yang akan dibuat dalam penelitian ini adalah sebuah sistem pendingin berupa kondensor yang akan menggantikan fungsi dari kolam pendingin yang telah ada.

Adapun dimensi dari kondensor yang dibuat adalah :

1. Tinggi tangki $240 \mathrm{~cm}$

2. Diameter tangki $153 \mathrm{~cm}$

3. Diameter spiral $140 \mathrm{~cm}$

4. Spiral terbuat dari bahan stainless steel berdiameter 2 inchi dengan ketebalan $1 \mathrm{~mm}$

5. Jarak antar spiral $10 \mathrm{~cm}$

Skema rancangan kondensor yang dibuat dapat dilihat pada Gambar 3 di bawah ini.

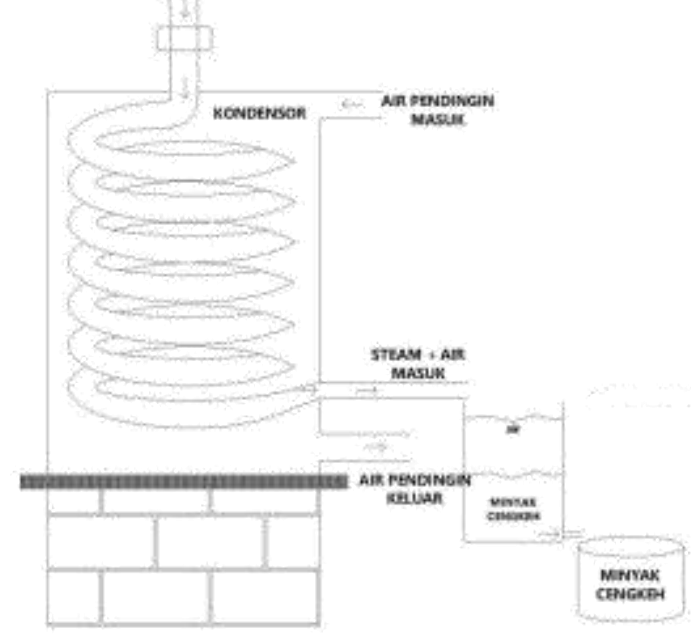

Gambar 3. Desain kondensor
Kondensor yang sudah jadi dan diaplikasikan oleh kelompok usaha "Rejo Tumetes" sebagai pendingin uap hasil penyulingan daun cengkeh ditunjukkan pada Gambar 4 dan Gambar 5.

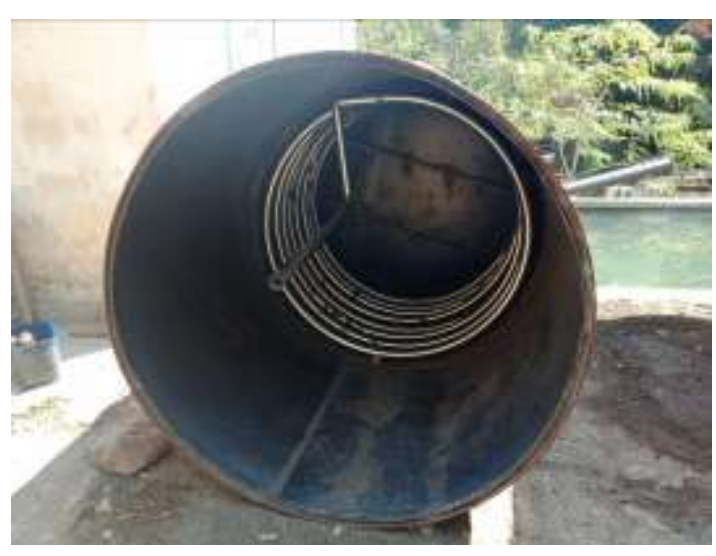

Gambar 4. Kondensor tampak dari depan

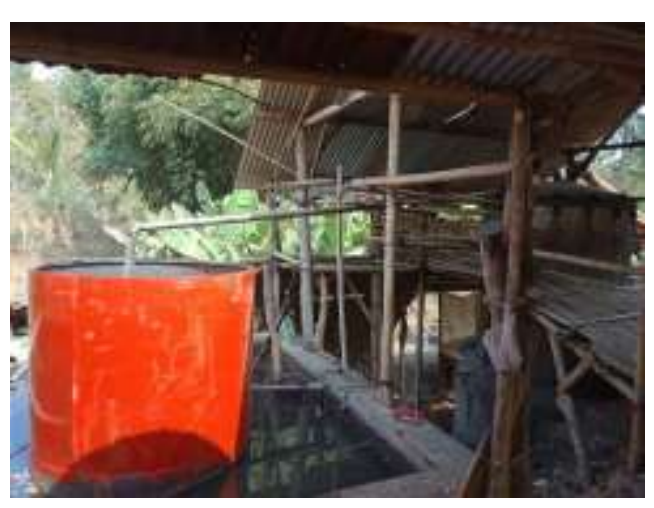

Gambar 5. Kondensor diaplikasikan pada sistem penyulingan

\section{ULASAN KARYA}

Dalam pelaksanaan program

Pengabdian Kepada Masyarakat ini kelompok usaha "Rejo Tumetes" sangat terbantu dengan adanya alat pendingin (kondensor) tersebut. Mereka dapat menghemat baik dari sisi waktu maupun tenaga yang dikeluarkan. Pada awalnya sistem penyulingan kelompok ini membutuhkan waktu sekitar 8-9 jam, setelah menggunakan kondensor waktu 
penyulingan dapat dikurangi menjadi sekitar 6 jam. Hal ini tentu akan menghemat juga bahan bakar dan tenaga yang dibutuhkan. Selain itu, dengan adanya kondensor ini dapat meningkatkan rendemen minyak cengkeh menjadi sekitar 2,5\%. Namun, ada beberapa kendala yang dihadapi dalam pelaksanaan program ini diantaranya jauhnya lokasi pembelian bahan kondensor yang mencapai jarak hingga $24 \mathrm{~km}$ sehingga proses pembuatan alatnya kurang berjalan lancar.

\section{DAMPAK DAN MANFAAT KEGIATAN}

Program ini memberikan dampak dan manfaat yang sangat besar terhadap kelompok penyuling minyak cengkeh di desa Kare kabupaten Madiun. Dimana mereka sudah bisa membuat secara mandiri alat pendingin berupa kondensor sehingga diharapkan dapat mempercepat proses penyulingan minyak cengkeh dan mengurangi beban masyarakat terhadap ketersediaan air di musim kemarau.

\section{KESIMPULAN}

Berdasarkan hasil yang telah dicapai dari kegiatan pengabdian masyarakat ini dapat disimpulkan bahwa program pengabdian masyarakat pada kelompok usaha penyulingan minyak cengkeh di desa kare terdiri dari beberapa tahap dimulai dengan penyuluhan/sosialisasi, pembuatan alat dan pendampingan di lapangan. Selain itu, antusiasme masyarakat terhadap program ini sangat tinggi hal ini dibuktikan dengan adanya peran serta masyarakat langsung dalam proses kegiatan awal sampai selesainya program ini. Rasa ingin tahu yang tinggi terkait bagaimana pembuatan alat tersebut agar proses penyulingan minyak cengkeh dapat berjalan efektif dan efisien.

\section{PENGHARGAAN}

Ucapan terima kasih kepada Direktorat Riset dan Pengabdian Masyarakat (DRPM) Direktorat Jenderal Penguatan Riset dan Pengembangan Kementerian Riset, Teknologi dan Pendidikan Tinggi (Kemenristekdikti) yang telah memberikan dana dan dukungan kepada tim sehingga Program Kemitraan Masyarakat (PKM) ini dapat berjalan lancar. Ucapan terima kasih juga disampaikan kepada ketua Kelompok Usaha "Rejo Tumetes" Bapak Matius S.Santoso yang telah memberikan kesempatan kepada tim PKM untuk melakukan program Pengabdian Kepada Masyarakat serta seluruh warga masyarakat desa Kare khususnya para penyuling minyak cengkeh yang turut berpartisipasi aktif dalam kegiatan ini.

\section{DAFTAR PUSTAKA}

[1] J. T. Yuhono, B. Penelitian, and T. Obat, "Status Pengusahaan Minyak Atsiri Dan Faktor-Faktor Teknologi Pasca Panen Yang Menyebabkan Rendahnya Rendemen Minyak," Bul. Penelit. Tanam. Rempah dan Obat, vol. 17, no. 2, pp. 79-90, 2015.

[2] Sumarni, N. B. Aji, and Solekan, "Pengaruh Volume Air Dan Berat Bahan Pada Penyulingan Minyak Atsiri," Teknologi, vol. 1, no. 1, pp. 83-88, 2008.

[3] K. S. Nugraheni, L. U. Khasanah, R. Utami, and B. K. Ananditho, 
"Pengaruh Perlakuan Pendahuluan Dan Variasi Metode Destilasi Terhadap Karakteristik Mutu Minyak Atsiri Daun Kayu Manis (C. Burmanii)," J. Teknol. Has. Pertan., vol. IX, no. 2, pp. 51-64, 2016.

[4] B. P. dan P. P. M. Ma'mun, "Penyulingan Minyak Atsiri," Inf. Teknol. Tanam. Rempah Dan Obat, pp. 1-26, 2014.

[5] Guenther, E., (1987), "Minyak Atsiri”, Jilid I, Penerjemah : S. Ketaren, hal. 19-20, 99-274. Penerbit Universitas Indonesia. Jakarta. 